Research

\title{
Tuberculosis treatment adherence and fatality in Spain
}

Joan A Caylà*1,2, Teresa Rodrigo 1,3, Juan Ruiz-Manzano1,4,10, José A Caminero 1,5, Rafael Vidal1,6,10, José M García1,7, Rafael Blanquer ${ }^{1,8}$, Martí Casals ${ }^{1,9}$ and the Working Group on Completion of Tuberculosis Treatment in Spain (Study ECUTTE)

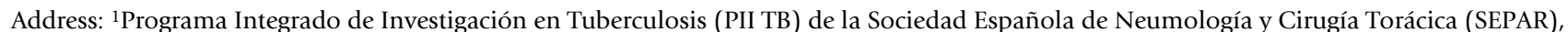
Spain, ${ }^{2}$ Unidad de Investigación de Tuberculosis de Barcelona, Servicio de Epidemiología de la Agencia de Salud Pública de Barcelona, Barcelona, Spain, ${ }^{3}$ Fundación Respira de la SEPAR, Barcelona, Spain, ${ }^{4}$ Hospital Universitario Germans Trías y Pujol de Badalona, Badalona, Spain, ${ }^{5}$ Hospital General Universitario de Gran Canaria Dr Negrín, Canary Islands, Spain, ${ }^{6}$ Hospital Vall D'Hebrón de Barcelona, Barcelona, Spain, ${ }^{7}$ Hospital San Agustín, Avilés, Asturias, Spain, ${ }^{8}$ Hospital Universitario Dr Peset de Valencia, Valencia, Spain, ${ }^{9}$ CIBER de Epidemiología y Salud Pública (CIBERESP), Barcelona, Spain and ${ }^{10}$ CIBER de Enfermedades Respiratorias (CIBERES), Barcelona, Spain

Email: Joan A Caylà* - jcayla@aspb.es; Teresa Rodrigo - trodrigo@aspb.es; Juan Ruiz-Manzano - jruizmanzano.germanstrias@gencat.net; José A Caminero - jcamlun@gobiernodecanarias.org; Rafael Vidal - ravidal@vhebron.net; José M García - josemaria.garciag@sespa.princast.es; Rafael Blanquer - blanquer_raf@gva.es; Martí Casals - mcasals@aspb.es; the Working Group on Completion of Tuberculosis Treatment in Spain (Study ECUTTE) - pii_secretaria@separ.es

* Corresponding author

Published: I December 2009

Respiratory Research 2009, 10:121 doi:10.1186/1465-9921-10-121
Received: 8 July 2009

Accepted: I December 2009

This article is available from: http://respiratory-research.com/content/10/1//2 I

(C) 2009 Caylà et al; licensee BioMed Central Ltd.

This is an Open Access article distributed under the terms of the Creative Commons Attribution License (http://creativecommons.org/licenses/by/2.0), which permits unrestricted use, distribution, and reproduction in any medium, provided the original work is properly cited.

\begin{abstract}
Background: The adherence to long tuberculosis (TB) treatment is a key factor in TB control programs. Always some patients abandon the treatment or die. The objective of this study is to identify factors associated with defaulting from or dying during antituberculosis treatment.

Methods: Prospective study of a large cohort of TB cases diagnosed during 2006-2007 by 6I members of the Spanish Society of Pneumology and Thoracic Surgery (SEPAR). Predictive factors of completion outcome (cured plus completed treatment vs. defaulters plus lost to follow-up) and fatality (died vs. the rest of patients) were based on logistic regression, calculating odds ratios (OR) and $95 \%$ confidence intervals $(\mathrm{Cl})$.

Results: Of the 1490 patients included, $29.7 \%$ were foreign-born. The treatment outcomes were: cured 792 (53.2\%), completed treatment $540(36.2 \%)$, failure $2(0.1 \%)$, transfer-out $33(2.2 \%)$, default $27(1.8 \%)$, death $27(1.8 \%)$, lost to follow-up 65 (4.4\%), other $4(0.3 \%)$. Completion outcome reached $93.5 \%$ and poor adherence was associated with: being an immigrant $(\mathrm{OR}=2.03$; $\mathrm{Cl}: \mathrm{I} .06-3.88)$, living alone $(\mathrm{OR}=2.35$; $\mathrm{Cl}: \mathrm{I} .05-5.26)$, residents of confined institutions $(\mathrm{OR}=$ 4.79; Cl:I.74-I3.I4), previous treatment (OR = 2.93; Cl:I.44-5.98), being an injecting drug user (IDU) $(\mathrm{OR}=9.5 \mathrm{I}$; $\mathrm{Cl}: 2.70-33.47)$ and treatment comprehension difficulties $(\mathrm{OR}=2.93 ; \mathrm{Cl}: \mathrm{I} .44-5.98)$. Case fatality was $1.8 \%$ and it was associated with the following variables: age 50 or over $(O R=10.88 ; \mathrm{Cl}: 1.12-105.01)$, retired $(O R=12.26 ; C l: 1.74-86.04)$, HIV-infected (OR = 9.93; Cl:I.48-66.34), comprehension difficulties (OR = 4.07; Cl:I.24-I3.29), IDU (OR = 23.59; $\mathrm{Cl}$ 2.46-225.99) and Directly Observed Therapy (DOT) (OR = 3.54; Cl: I.07-I I.77).

Conclusion: Immigrants, those living alone, residents of confined institutions, patients treated previously, those with treatment comprehension difficulties, and IDU patients have poor adherence and should be targeted for DOT. To reduce fatality rates, stricter monitoring is required for patients who are retired, HIV-infected, IDU, and those with treatment comprehension difficulties.
\end{abstract}




\section{Introduction}

Tuberculosis (TB) is an infectious disease requiring adherence to long-term treatment and the tracing of patient's contacts, thus justifying it being a notifiable disease in most countries of the world. This ancient disease continues to be an important public health problem, and for this reason the World Health Organisation (WHO) declared it to be a global emergency in 1993 [1]. In 2007 it was estimated that, worldwide, there had been 9.27 million new cases and 1.756 million deaths from $\mathrm{TB}$, of which 1.37 million cases and 0.456 million deaths were among HIVinfected individuals[2]. Moreover, to these new cases one must add the millions already in existence, making it the most prevalent infectious disease[3].

The rise of immigration over the last decade in Spain has substantially altered the characteristics of TB patients. The Spanish population was $45,200,737$ inhabitants in 2007, of whom 4,419,554 (9.99\%) were foreign-born[4]. In Barcelona, a city with one of the highest influxes of immigrants, the percentage of foreign-born TB patients rose from $5 \%$ in 1995 to $46 \%$ in 2007 (with incidence rates among immigrants of over 100 cases per 100,000 inhabitants) [5].

The Tuberculosis and Respiratory Infections section of SEPAR (Spanish Society of Pneumology and Thoracic Surgery) has previously published a study on adherence to anti-tuberculosis treatment and on fatality, referring to a cohort of patients followed during the period 1999 to 2000[6]. The findings indicated that immigrant status and being an injecting drug user were associated with worse treatment adherence, while patients who were HIVinfected, alcoholics, or of advanced age presented higher fatality.

The aims of the present study were to analyse antituberculosis treatment adherence and fatality during standard TB treatments in patients with TB in Spain, and to identify factors associated with these events. The study will also permit changes in relation to the earlier study[6] to be assessed, and to determine whether demographic changes experienced in Spain due to the considerable rise in immigration have had any influence on adherence to tuberculosis treatment.

\section{Methods}

A multicentric prospective study was carried out involving prospective follow-up of an extensive cohort of $\mathrm{TB}$ patients, provided by 61 collaborators from 53 hospitals throughout Spain. The study was promoted by the Integrated TB Research Programme of SEPAR. Patients diagnosed with TB between 1 January 2006 and 31 December 2007 , aged 18 years or over, were included. Those patients with known resistances were excluded, as were those in whom initiation of standard TB treatment was not advisable, such as patients with hepatic problems. Cases were followed up according to an evaluation calendar (Table 1). An informed consent to participate in the study was elicited.

The information collected covered the following aspects: sociodemographic data, toxic habits, clinical history, diagnostic methods, drug-susceptibility, medication, clinical course, and adherence to and outcome of treatment. Data was collected through an electronic diary made available through a computerised application, accessed by each study collaborator via the SEPAR Web site using a personalised username and password.

Any patient born outside Spain was classified as an immigrant. Men consuming over $280 \mathrm{~g}$ of alcohol per week, and women over $168 \mathrm{~g}$, were considered alcoholics. Intravenous users of illegal drugs (heroin and cocaine) were classified as intravenous drug users (IVDU). Toxicity was defined as an adverse effect that requires to change at least one drug, and treatment comprehension was defined as the perception of the treating doctors of the patient. The chest X-Rays were performed at the moment of the diagnosis and at the $2^{\text {nd }}$ and $6^{\text {th }}$ month and when necessary, and the evolution was classified by the treating doctor of the patient as improvement, stable or progression.

During these years the standard treatment for TB in Spain for new cases were: 2 months of rifampicin (R), isoniazid $(\mathrm{H})$ and pirazinamide $(\mathrm{Z})$ followed by 4 months of $\mathrm{RH}$ $(2 \mathrm{RHZ}+4 \mathrm{RH})$ or the same treatment plus Ethambutol (E) during the first 2 months ${ }^{20}(2 \mathrm{RHZE}+4 \mathrm{RH})$. In Spain DOTS is a priority only for patients with high risk of bad adherence (IVDU, homeless, prisoners, etc). A patient was included in the previous treatment category only if he or she had taken antituberculosis treatment over one year before the current active TB episode.

Control of questionnaire completion and the database was carried out via telephone and e-mail contacts between the field worker and study collaborators.

The following definitions were employed for treatment outcome, in accordance with European recommendations[7]:

Cured: when the patient has completed a full course of anti-TB therapy and a negative culture is obtained during the continuation phase (culture-positive patients) or two negative sputum smears during the continuation phase, one of which must be at the end of treatment (patients diagnosed by microscopy). 
Table I: Patient evaluation calendar

\begin{tabular}{|c|c|c|c|}
\hline & $\begin{array}{c}\text { Visit I } \\
\text { Diagnosis }\end{array}$ & $\begin{array}{c}\text { Visit } 2 \\
2 \text { Months }\end{array}$ & $\begin{array}{l}\text { Visit } 3 * \\
6 \text { Months }\end{array}$ \\
\hline Criteria of inclusion/exclusion & $x$ & & \\
\hline Sociodemographic data & $x$ & & \\
\hline Tobacco, alcohol, drug use & $x$ & & \\
\hline Anthropometric data & $x$ & $x$ & $x$ \\
\hline Clinical history & $x$ & & \\
\hline Diagnostic method employed & $\mathrm{X}$ & & \\
\hline Medication & $x$ & $x$ & $x$ \\
\hline Clinical course & & $x$ & $x$ \\
\hline Adherence to treatment & & $x$ & $x$ \\
\hline Collection of samples & $x$ & $x$ & $x$ \\
\hline Drug sensitivity test & $x$ & & \\
\hline Treatment outcome & & & $x$ \\
\hline Informed consent & $x$ & & \\
\hline
\end{tabular}

* For long treatments new visits are recommended at 9,12,18 months.

Treatment completed: if the course of treatment prescribed was completed but no bacteriological conversion occurred (culture-positive patients) or no smear result is available at the end of treatment (patients diagnosed by microscopy).

Default: If the patient interrupts the treatment for any reason for more than two months, if there is a non-completion of treatment within 9 months when the patient is placed on a six-month regimen, or if the drug intake was $<80 \%$ of the prescribed dose.

Treatment failure: A patient who fails to achieve bacteriological conversion within 5 months after the start of treatment or, after previous conversion, becomes sputum smear or culture positive again.

Death: A patient who died of any cause during the course of treatment is recorded under death.

In the present study, the category of transfer out[7] was redefined into two subcategories:
Lost to follow-up: when it is known that the patient disappeared and no additional information is available.

Transfer out: when a patient moves to another town or health centre and whose follow-up (with medical report available) is the responsibility of a doctor not collaborating in the present study.

The results of the analysis were summarized as:

Successful outcome: the percentage of patients who were cured or completed treatment out of all those detected.

Completion outcome: the percentage of patients who were cured or completed treatment out of all patients who were cured or completed treatment, were defaulters, or were lost to follow up.

Case-fatality rate: the percentage of patients who died during TB treatment out of all patients who were cured or completed treatment or were defaulters. 
Potentially unsatisfactory outcome: the percentage of patients who interrupted treatment, were lost to follow up, or failed treatment out of all detected patients.

In accordance with guidelines of the Council for International Organizations of Medical Sciences (CIOMS, Geneva, 1991), and with recommendations of the Spanish Epidemiology Association regarding review of ethical aspects of epidemiological studies, the present study was submitted for evaluation to the Research Ethical Committee of the Teknon Medical Center, Barcelona and was approved on February 24th 2006 . All records with patients were identified were confidential and handled in accordance with the Spanish Data Protection Law 15/ December13th, 1999 (Protección de Datos de Carácter Personal). Principles of the Helsinki Declaration were followed at all times. Each patient had an informed consent card read aloud to them.

\section{Statistical analysis}

A descriptive study was carried out of the qualitative and quantitative variables collected in order to characterise the study population. Frequency distributions and medians for quantitative variables were calculated. Proportions were compared between groups using $\chi^{2}$ tests, and when pertinent, the two-sided Fisher test. Quantitative variables were compared using Student's t-test or its non-parametric equivalent, the Mann-Whitney U-test, when assumptions of normality and homogeneity of variances were not met. Measures of association were calculated using odds ratios (OR) along with their 95\% confidence intervals (CI). The analysis of factors associated with poor adherence treatment defaulting (comparing: cured plus treatment completed $v$ s. defaulters plus lost to follow-up) and of fatality (comparing: died $v s$. the rest of patients) were analysed using logistic regression (stepwise method) including in the model the variables associated at the univariate level with a p-value $<0.15$. A p-value of under 0.05 was considered significant. The test of Hosmer and Lemeshow was used to check the goodness-of-fit of the models. Analyses were conducted using the SPSS statistical package, version 13.0 (SPSS Inc, Chicago, IL, USA).

\section{Results}

The number of patients included initially was 1500, however $10(0.6 \%)$ had to be excluded for not meeting any inclusion criteria, so the final number of patients analysed was 1490 (table 2). The majority were males, aged $>31$ years old, native, occupationally active, lived with their families, diagnosed via emergency services, had pulmonary $\mathrm{TB}$, either smokers or ex-smokers, initially treated with three drugs, and who understood well the implications of having TB and its treatment. They were also characterised by low frequencies of HIV infection, IDU, alcoholism, previous TB treatment, low levels of drug resistances, toxicities to drugs, and of treatment via DOT. Table 2 presents the final outcomes of therapy, where it may be noted that $89.4 \%$ of cases were cured or completed treatment. It is estimated that $1.8 \%$ defaulted, and $4.4 \%$ of cases were lost to follow-up and probably did not complete treatment.

According to these data, the outcome was 'successful' in $89.4 \%$ of patients considering all cases and $83.1 \%$ considering only smear-positive cases. Completion was $93.5 \%$ considering all TB cases and $92.4 \%$ considering only smear-positive cases. Among the immigrants, these percentages were 87.8 and 88.3 , respectively. The outcome of 'potentially unsatisfactory' accounted for $6.3 \%$ of all cases and $7.4 \%$ for smear-positive cases.

The analysis of factors possibly associated to poor adherence are presented in table 3. As presented in the table, at the univariate level poorer adherence was observed for men, immigrants, younger patients, those not retired, those not living with their family, HIV-infected patients, previously treated subjects, those who had difficulty understanding the treatment, those diagnosed via emergency services, and IDU patients, whereas being in DOT had no influence. Multivariate analysis confirmed the influence of being an immigrant, living alone, being residents of confined institutions, previous TB treatment, having difficulty understanding the treatment, and being IDU.

The case-fatality was $1.8 \%$. The analysis of factors associated with fatality is presented in table 4 . Variables having an influence at the univariate level were: immigrant, disabled or retired, residents of confined institutions or incarcerated, HIV-infected, IDU, no radiological improvement, and being in DOT. Multivariate analysis confirmed the influence of being aged over 50, being retired, being HIVinfected, having comprehension difficulties, being IDU, and having been treated under DOT.

\section{Discussion}

In the present study, the completion outcome was $93.5 \%$ and the treatment success outcome was $89.4 \%$, better percentages than observed in the previous study conducted by our group [6]. A study in England, Wales and Northern Ireland found a treatment success of $79 \%$ when calculated for cases in which outcome information was reported and $62 \%$ for all cases [8]. The treatment completion outcome published by the Barcelona Tuberculosis Control Program was 95.9\%[9]. However, according to several studies, antituberculosis therapy adherence percentages are variable: USA[10] (91.2\%); San Francisco[11] (88.6\%); Norway[12] (83\%); Europe[13] (69\%) although the way in which theses percentages are calculated could have some influence. 
Table 2: Distribution of patients in terms of study variables.

\begin{tabular}{|c|c|c|}
\hline Variables & & $\mathbf{N}(\%)$ \\
\hline \multirow[t]{2}{*}{ SEX } & Men & $920(63.4)$ \\
\hline & Women & $532(36.6)$ \\
\hline \multirow[t]{2}{*}{ COUNTRY } & Immigrant & $442(29.7)$ \\
\hline & Native & $1048(70.3)$ \\
\hline \multirow[t]{3}{*}{ AGE } & $18-30$ & $497(33.4)$ \\
\hline & $31-50$ & $596(40.0)$ \\
\hline & $>50$ & $397(26.6)$ \\
\hline \multirow[t]{5}{*}{ OCCUPATIONAL STATUS } & Active & $901(60.5)$ \\
\hline & Disabled & $68(4.5)$ \\
\hline & Unemployed & $257(17.2)$ \\
\hline & Retired & $220(14.8)$ \\
\hline & Unknown & $44(3.0)$ \\
\hline \multirow[t]{5}{*}{ LIVING ARRANGEMENTS } & Alone & $157(10.5)$ \\
\hline & Confined institutions & $54(3.6)$ \\
\hline & Shared accommodation & $189(12.7)$ \\
\hline & Family & $1062(71.3)$ \\
\hline & Unknown & $28(1.9)$ \\
\hline \multirow[t]{4}{*}{ SOURCE } & Hospital emergency department & $682(45.8)$ \\
\hline & Primary Health Care & $268(18.0)$ \\
\hline & Specialist & $210(14.1)$ \\
\hline & Unknown & $330(22.1)$ \\
\hline \multirow[t]{3}{*}{ HIV-infected } & No & $1060(71.2)$ \\
\hline & Yes & $66(4.4)$ \\
\hline & Unknown & $364(24.4)$ \\
\hline \multirow[t]{3}{*}{ INTRAVENOUS DRUG USERS } & No & $872(58.5)$ \\
\hline & Yes & $21(1.4)$ \\
\hline & Unknown & $597(40.1)$ \\
\hline \multirow[t]{4}{*}{ LOCALIZATION } & Pulmonary & $1249(83.8)$ \\
\hline & Extrapulmonary & $159(10.7)$ \\
\hline & Mixed & $67(4.5)$ \\
\hline & Unknown & $15(1.0)$ \\
\hline \multirow[t]{3}{*}{ ALCOHOL USE } & No & $1064(7 \mid .4)$ \\
\hline & Yes & $375(25.2)$ \\
\hline & Unknown & $51(3.4)$ \\
\hline \multirow[t]{3}{*}{ SMOKING } & Non-smoker & $676(45.4)$ \\
\hline & Smoker or ex smoker & $797(53.5)$ \\
\hline & Unknown & $17(1.1)$ \\
\hline \multirow[t]{3}{*}{ INITIAL THERAPY } & 3 Drugs & $770(5 \mathrm{I} .7)$ \\
\hline & 4 Drugs & $649(43.5)$ \\
\hline & Unknown & $71(4.8)$ \\
\hline \multirow[t]{3}{*}{ DRUG RESISTANCE* } & No & $864(80.1)$ \\
\hline & Yes & $85(7.9)$ \\
\hline & Unknown & $129(12.0)$ \\
\hline \multirow[t]{2}{*}{ TOXICITY } & Yes & $74(5.0)$ \\
\hline & No & $1416(95.0)$ \\
\hline
\end{tabular}


Table 2: Distribution of patients in terms of study variables. (Continued)

\begin{tabular}{|c|c|c|}
\hline PREVIOUS TREATMENT & Yes & $|3|(9.0)$ \\
\hline & No & $1320(9 \mid .0)$ \\
\hline \multirow[t]{2}{*}{ DIRECTLY OBSERVED TREATMENT } & No & $1338(89.8)$ \\
\hline & Yes & $152(10.2)$ \\
\hline \multirow[t]{3}{*}{ TREATMENT COMPREHENSION } & Easy & $1266(85.0)$ \\
\hline & Difficult & 139 (9.3) \\
\hline & Unknown & $85(5.7)$ \\
\hline \multirow[t]{8}{*}{ FINAL OUTCOME } & Cured & $792(53.2)$ \\
\hline & Completed treatment & $540(36.2)$ \\
\hline & Failure & $2(0.1)$ \\
\hline & Transfer out & $33(2.2)$ \\
\hline & Default & $27(1.8)$ \\
\hline & Death & $27(1.8)$ \\
\hline & Lost to follow up & $65(4.4)$ \\
\hline & Other & $4(0.3)$ \\
\hline
\end{tabular}

*Only patients with positive culture

In our opinion, completion outcome is a better indicator of adherence than successful outcome because is not influenced by the number of deaths (sometimes related to old patients or co morbidities but not to the quality of the Program). It is therefore essential to unify definition criteria: even though there is agreement over how to calculate the successful outcome, different methodologies are employed in calculating completion, making comparisons difficult. We consider that the ideal formula for calculating completion outcomes is that used in the present study (percentage of patients who were cured or completed treatment out of all patients who were cured or completed treatment, were defaulters, or were lost to follow-up). Furthermore, we believe it would be important to add the category 'lost to follow-up' to the European definition when it is known that the patient disappeared and no additional information is available, only considering as 'transfer out' a patient who moves to another town or changes to another health centre and whose follow-up is performed by some other physician not collaborating in the study.

Several risk factors of poor adherence have already been identified in other studies (residents of confined institutions, incarcerated, IDU, previous antituberculosis treatment, HIV-infected and immigrant) $[8,14]$. In our earlier study $[6]$, the variables found to be associated were IDU and immigration while sex, age, and residents of confined institutions, incarceration, DOT or hospitalisation were not associated. In the present study, IDU and immigrant status continue to be associated, and we have also detected the influence of living alone, being residents of confined institutions, having difficulty understanding the treatment, and having previously undergone antiTB treatment. Sex, age group, occupational status, HIV status and having been diagnosed via emergency department had no influence. It is worth stressing the importance of not living with a family and the initial assessment made by the clinician in relation to the ease with which the patient comprehends the treatment. Many of those having difficulty understanding the treatment were immigrants, although some were native patients.

The case-fatality rate is low compared with other studies[15] due to the fact that in our study one of the criteria for exclusion was non-applicability of standard treatment for whatever reason (known resistances, various types of co morbidity), and also due to the fact that the frequency of HIV-infected patients with neoplasms or of advanced age was relatively low. In an European study, it was observed that advancing age and resistance to isoniazid and rifampicin were the strongest determinants of death, while male sex, European origin, pulmonary site of disease and previous anti-TB treatment were weaker predictors[16]. In an inner-city cohort, underlying illnesses such as diabetes mellitus, renal failure, chronic obstructive pulmonary disease, and HIV infection were predictors of death[17]. In Mexico, predictors of death included delays in treatment after onset of the disease and low adherence of patients to the treatment regime[18].

In our first study, the variables found to be predictive of fatality were alcoholism, HIV infection and age $>64$ years, whereas sex, IDU, residents of confined institutions, DOT 
Table 3: Analysis of factors associated with poor adherence to antituberculosis treatment.

\begin{tabular}{|c|c|c|c|c|c|c|c|c|}
\hline \multirow[b]{2}{*}{ Variables } & & \multirow[b]{2}{*}{$\mathbf{N}$ (\%defaulters) } & \multicolumn{3}{|c|}{ UNIVARIATE ANALYSIS $(p \leq 0.05)$} & \multicolumn{3}{|c|}{$\begin{array}{l}\text { MULTIVARIATE ANALYSIS }(p \leq \\
0.05)\end{array}$} \\
\hline & & & p-value & OR & $95 \% \mathrm{Cl}$ & p-value & OR & $95 \% \mathrm{Cl}$ \\
\hline \multirow[t]{2}{*}{ SEX } & Men & $880(7.5)$ & 0.015 & 1.87 & $1.13-3.09$ & & & \\
\hline & Women & $506(4.2)$ & & 1 & & & & \\
\hline \multirow[t]{2}{*}{ COUNTRY } & Immigrant & $420(12.1)$ & $<0.001$ & 3.24 & $2.11-4.98$ & 0.031 & 2.03 & $1.06-3.88$ \\
\hline & Native & $1004(4.1)$ & & 1 & & & 1 & \\
\hline \multirow[t]{3}{*}{ AGE } & $18-30$ & 479 (8.I) & 0.019 & 2.08 & $1.12-3.83$ & & & \\
\hline & $31-50$ & $578(6.6)$ & 0.109 & 1.65 & $0.89-3.04$ & & & \\
\hline & $>\mathbf{5 0}$ & $367(4.1)$ & & 1 & & & & \\
\hline \multirow{4}{*}{$\begin{array}{l}\text { OCCUPATIONAL } \\
\text { STATUS }\end{array}$} & Active & $876(6.1)$ & 0.028 & 3.17 & $1.13-8.86$ & & & \\
\hline & Disabled & $61(8.2)$ & 0.031 & 4.39 & $1.14-16.92$ & & & \\
\hline & Unemployed & 244 (II.I) & 0.001 & 6.12 & $2.10-17.82$ & & & \\
\hline & Retired & $201(2.0)$ & & 1 & & & & \\
\hline \multirow{4}{*}{$\begin{array}{l}\text { LIVING } \\
\text { ARRANGEMENTS }\end{array}$} & Alone & $145(10.3)$ & $<0.001$ & 3.27 & $1.74-6.16$ & 0.037 & 2.35 & $1.05-5.26$ \\
\hline & $\begin{array}{l}\text { Confined } \\
\text { institutions }\end{array}$ & $45(24.4)$ & $<0.001$ & 9.18 & $4.30-19.62$ & 0.002 & 4.79 & $1.74-13.14$ \\
\hline & Sharing accom. & $180(12.2)$ & $<0.001$ & 3.95 & $2.26-6.91$ & 0,263 & 1,59 & $0,70-3,62$ \\
\hline & Family & $1029(3.4)$ & & 1 & & & 1 & \\
\hline \multirow[t]{3}{*}{ HIV-infected } & Yes & $60(13.3)$ & 0.029 & 2.40 & $1.09-5.29$ & & & \\
\hline & Unknown & $349(6.6)$ & 0.697 & 1.10 & $0.67-1.81$ & & & \\
\hline & No & $1015(6.0)$ & & 1 & & & & \\
\hline \multirow{4}{*}{$\begin{array}{l}\text { PREVIOUS } \\
\text { TREATMENT } \\
\text { COMPREHENSION }\end{array}$} & Yes & $12 \mid(17.4)$ & $<0.001$ & 3.75 & $2.20-6.30$ & 0.009 & 2.80 & $1.29-6.08$ \\
\hline & No & $1264(5.3)$ & & 1 & & & 1 & \\
\hline & Difficult & $122(\mid 1.5)$ & 0.001 & 3.60 & $1.91-6.79$ & 0.003 & 2.93 & $1.44-5.98$ \\
\hline & Easy & $1238(3.5)$ & & 1 & & & I & \\
\hline \multirow[t]{4}{*}{ SOURCE } & Emergencies & $646(9.0)$ & 0.006 & 2.76 & $1.34-5.66$ & & & \\
\hline & Primary Care & $261(3.4)$ & & 1 & & & & \\
\hline & Specialist & $203(4.4)$ & 0.587 & 1.29 & $0.50-3.33$ & & & \\
\hline & Other & $314(5.1)$ & 0.338 & 1.50 & $0.65-3.46$ & & & \\
\hline \multirow{3}{*}{$\begin{array}{l}\text { INTRAVENOUS } \\
\text { DRUG USERS }\end{array}$} & No & $830(4.5)$ & & 1 & & & 1 & \\
\hline & Yes & $19(21.1)$ & 0.003 & 5.71 & $1.80-18.07$ & 0.001 & 9.51 & $2.70-33.47$ \\
\hline & Unknown & 575 (8.9) & 0.001 & 2.08 & $1.34-3.23$ & 0.027 & 2.00 & $1.08-3.72$ \\
\hline \multirow{2}{*}{$\begin{array}{l}\text { DIRECTLY } \\
\text { OBSERVED } \\
\text { TREATMENT }\end{array}$} & Yes & $140(7.1)$ & 0.730 & 1.12 & $0.57-2.22$ & & & \\
\hline & No & $1284(6.4)$ & & I & & & & \\
\hline
\end{tabular}

Also had no influence at univariate level: resistance, alcohol, smoking, radiology, and localization.

$\mathrm{Cl}$ : Confidence Interval

OR: Odds ratio 
and hospitalisation were not. In the present study, the influence of HIV and of retirement (a "proxy" of older age) is confirmed, and in addition we identify being aged over 50, being IDU, difficulties in comprehending the treatment, and being treated under DOT. In contrast, sex, immigrant status, sharing accommodation, previous antituberculosis treatment, radiological evolution, and alcoholism had no influence. When the two studies are compared, the distribution by sex, age-group and other variables are fairly similar, but the percentage of immigrants now is steadily increasing, as in other countries of Europe[19]. In relation to DOT, in the current study only $9.3 \%$ of patients were under this treatment, and in general doctors prioritise DOT for more complicated patients. In any case, it should be emphasised from analysing the predictor variables in the present study that the variable of understanding the treatment is very important not only for adherence, but also for fatality. Therefore, patients in whom the clinician observes this difficulty should be candidates for DOT and for closer monitoring in general.

In regard to the type of therapy applied, it was observed that, in line with Spanish recommendations during these years and given the low rates of primary resistance to isoniazid, the majority of native patients had received treatment with three drugs (fixed dose combinations of rifampicin, isoniazid and pyrazinamide) whereas foreignborn patients (with a higher proportion of resistance to isoniazid) were recommended to take four drugs[20], i.e. adding ethambutol. It has recently been observed that there is a progressive rise in resistances[21,22] and that this is particularly the case in the immigrant population, and hence the use of four drugs has been recommended in the treatment of incident TB patients[23], in line with both USA[24] and UK[25] guidelines.

It should be noted that the present study was carried out by a scientific society of pneumologists, and that a considerable number of collaborators contributed an extensive cohort of patients. Follow-up of cases was exhaustive, although they cannot be extrapolated to all TB patients in Spain since the study involved physicians particularly motivated by this disease. It is therefore possible that percentages of defaulting and of fatality among TB cases in Spain would be somewhat higher in general. Another limitation of this study is that patients with TB drug resistance were not included because they can have prior history of abandonment of TB treatments.

In summary, the percentage of cases coming from foreign countries is greater than recorded previously[6]. Being an immigrant, living alone, being residents of confined institutions, having a history of antiTB treatment, having difficulty in understanding the treatment, and being IDU are all factors associated with poor adherence. Death was associated with patients who were: over the age of 50, retired, HIV-infected, IDU, having difficulty understanding treatment, and being treated according to DOT (explainable since it is applied above all in the most difficult patients[26]). Therefore, to improve adherence, special care should be taken to treat patients with social problems (DOT at home, methadone programs even in prisons, admission to TB DOT centres) [27]. To reduce fatality, earlier suspicion, diagnosis, and treatment are necessary, particularly among the elderly and those patients with comorbidity or immunodepression. Community health worker intervention[28] and closer monitoring is necessary for patients in whom the physician perceives any difficulty in understanding the treatment (whether immigrants or native); this would lead not only to improved adherence, but also to better survival among these TB patients.

\section{Conclusion}

It is important that every city, region or country studies adherence to $\mathrm{TB}$ treatment and its predictive factors. In our case, this study was performed by a national scientific society of pneumology and these results can help to improve the control of TB patients in our country, and in others.

\section{Competing interests}

The authors declare that they have no competing interests.

\section{Authors' contributions}

All authors read and approved the final manuscript. Specifically each author made the following contributions:

JAC, JRM, JC, RV, RB and JMG designed overall synthesis the study.

JAC and TR coordinated the research.

TR supervised data collection and MC analysed and interpreted the findings.

The Working Group on Completion of Tuberculosis Treatment in Spain collection the cases and reviewed the paper.

\section{Acknowledgements \\ Working Group on Completion of Tuberculosis Treatment in Spain (Study ECUTTE):}

R. Agüero (H Marqués de Valdecilla, Santander); J.L. Alcázar (Instituto Nacional de Silicosis, Oviedo); L. Altube (H Galdakao, Galdakao); L. Anibarro (Unidad de Tuberculosis de Pontevedra, Vigo); M. Barrón (H San Millán-San Pedro, Logroño); S. Benoliel (H 12 de Octubre, Madrid); L. Borderías ( $\mathrm{H}$ San Jorge, Huesca); A. Bustamante (H Sierrallana, Torrelavega); J.L. Calpe (H La Marina Baixa, Villajoyosa); E. Cases (H Universitario La Fe, Valencia); R. Castrodeza (H El Bierzo Ponferrada-León, Ponferrada); J.J. Cebrián (H Costa del Sol, Marbella); J. E. Ciruelos (Hospital de Cruces, Guetxo); M.L. De Souza (Unidad Prevención y Control Tuberculosis, Bar- 
Table 4: Analysis of factors associated with dying during the expected treatment period among patients with tuberculosis.

\begin{tabular}{|c|c|c|c|c|c|c|c|c|}
\hline \multirow[b]{2}{*}{ Variables } & & \multirow[b]{2}{*}{ N (\%deaths) } & \multicolumn{3}{|c|}{ UNIVARIATE ANALYSIS $(p \leq 0.05)$} & \multicolumn{3}{|c|}{ MULTIVARIATE ANALYSIS $(p \leq 0.05)$} \\
\hline & & & p-value & OR & $95 \% \mathrm{Cl}$ & p-value & OR & $95 \% \mathrm{Cl}$ \\
\hline \multirow[t]{3}{*}{ AGE } & $18-30$ & $497(0.2)$ & & 1 & & & & \\
\hline & $31-50$ & $596(0.8)$ & 0.191 & 4.19 & $0.48-36.03$ & & & \\
\hline & $>\mathbf{5 0}$ & $397(5.3)$ & 0.001 & 27.70 & $3.7 I-206.86$ & 0.039 & 10.88 & $1.12-105.01$ \\
\hline \multirow[t]{2}{*}{ SEX } & Men & $920(1.8)$ & 0.965 & 0.98 & $0.44-2.16$ & & & \\
\hline & Women & $532(1.9)$ & & 1 & & & & \\
\hline \multirow[t]{2}{*}{ COUNTRY } & Immigrant & $442(0.9)$ & 0.099 & 0.40 & $0.14-1.18$ & & & \\
\hline & Native & $1048(2.2)$ & & 1 & & & & \\
\hline \multirow{4}{*}{$\begin{array}{l}\text { OCCUPATIONAL } \\
\text { STATUS }\end{array}$} & Active & $901(0.4)$ & & 1 & & & & \\
\hline & Disabled & $68(5.9)$ & $<0.001$ & 14.01 & $3.42-57.34$ & & & \\
\hline & Unemployed & $257(0.8)$ & 0.516 & 1.75 & $0.32-9.65$ & & & \\
\hline & Retired & $220(6.8)$ & $<0.001$ & 16.40 & $5.39-49.95$ & 0.012 & 12.26 & $1.74-86.04$ \\
\hline \multirow{4}{*}{$\begin{array}{l}\text { LIVING } \\
\text { ARRANGEMENTS }\end{array}$} & Alone & $157(2.5)$ & 0.399 & 1.60 & $0.53-4.83$ & & & \\
\hline & $\begin{array}{l}\text { Confined } \\
\text { institutions }\end{array}$ & $54(5.6)$ & 0.045 & 3.61 & $1.02-12.73$ & & & \\
\hline & Sharing accom. & $189(0.5)$ & 0.279 & 0.32 & $0.04-2.47$ & & & \\
\hline & Family & $1062(1.6)$ & & 1 & & & & \\
\hline \multirow[t]{3}{*}{ HIV-INFECTED } & Yes & $66(7.6)$ & 0.001 & 5.71 & $2.00-16.22$ & 0.018 & 9.93 & $1.48-66.34$ \\
\hline & Unknown & 364 (1.9) & 0.499 & 1.36 & $0.55-3.37$ & & & \\
\hline & No & $1060(1.4)$ & & 1 & & & & \\
\hline \multirow{2}{*}{$\begin{array}{l}\text { PREVIOUS } \\
\text { TREATMENT }\end{array}$} & Yes & $|3|(3.8)$ & 0.092 & 2.34 & $0.87-6.28$ & & & \\
\hline & No & $1320(1.7)$ & & 1 & & & & \\
\hline \multirow[t]{2}{*}{ COMPREHENSION } & Difficult & $139(5.0)$ & $<0.001$ & 7.40 & $2.71-20.21$ & 0.020 & 4.07 & $1.24-13.29$ \\
\hline & Easy & $1266(0.7)$ & & 1 & & & & \\
\hline \multirow[t]{3}{*}{ ALCOHOL USE } & Yes & $375(2.4)$ & & 1 & & & & \\
\hline & No & $1064(1.5)$ & 0.258 & 0.621 & & & & \\
\hline & & & & & $0.27-1.4 \mid$ & & & \\
\hline \multirow{3}{*}{$\begin{array}{l}\text { INTRAVENOUS } \\
\text { DRUG USERS }\end{array}$} & No & $872(2.2)$ & & & & & & \\
\hline & Yes & $21(9.5)$ & 0.046 & 4.72 & $1.02-21.74$ & 0.006 & 23.59 & $2.46-225.99$ \\
\hline & Unknown & $597(1.0)$ & & 1 & & & & \\
\hline \multirow{3}{*}{$\begin{array}{l}\text { RADIOLOGICAL } \\
\text { EVOLUTION }\end{array}$} & Improvement & $982(0.6)$ & & 1 & & & & \\
\hline & $\begin{array}{l}\text { Stable/ } \\
\text { progression }\end{array}$ & $294(3.1)$ & 0.002 & 5.13 & $1.81-14.55$ & & & \\
\hline & Unknown & $214(5.6)$ & $<0.001$ & 9.66 & $3.58-26.04$ & & & \\
\hline \multirow{2}{*}{$\begin{array}{l}\text { DIRECTLY } \\
\text { OBSERVED } \\
\text { TREATMENT }\end{array}$} & Yes & $152(3.9)$ & 0.044 & 2.57 & $1.02-6.48$ & 0.038 & 3.54 & $1.07-11.77$ \\
\hline & No & $1338(1.6)$ & & I & & & & \\
\hline
\end{tabular}

Also had no influence at univariate level: resistance, smoking, and localization.

$\mathrm{Cl}$ : Confidence Interval

OR: Odds ratio 
celona); D. Díaz (Complejo Hospitalario Juan Canalejo, La Coruña); B. Fernández (H de Navarra, Pamplona); A. Fernández (H Río Carrión, Palencia); J. Gallardo (H General de Guadalajara, Guadalajara); M. Gallego (Corporación Sanitaria Parc Taulí, Sabadell); C. García (H General Isla Fuerteventura, Puerto del Rosario); F.J. García (H Universitario de la Princesa, Madrid); J.A. Gullón (Hospital Universitario de Canarias, La Laguna); M. Iglesias (H Marqués de Valdecilla, Santander); M.A. Jiménez (Unidad Prevención y Control Tuberculosis, Barcelona); J.M. Kindelan (H Universitario Reina Sofía, Córdoba); J. Laparra (H Donostia-San Sebastián, San Sebastián); T. Lloret (H General Universitario de Valencia, Valencia); M. Marín (H General de Castellón, Castellón); J.T. Martínez (H Mutua de Terrasa, Tarrasa); E. Martínez (H de Sagunto, Sagunto); A. Martínez (H de La Marina Baixa, Villajoyosa); J.F. Medina (H Universitario Virgen del Rocío, Sevilla); C. Melero ( $\mathrm{H} 12$ de Octubre, Madrid); C. Milà (Unidad Prevención y Control Tuberculosis, Barcelona); I. Mir (H Son Llatzer, Palma de Mallorca); M.A. Morales (Hospital Cruz Roja Inglesa, Ceuta); V. Moreno (H Carlos III, Madrid); L. Muñoz (H Reina Sofía, Córdoba); C. Muñoz (H Clínico Universitario de Valencia, Valencia); J.A. Muñoz-Calero (H Universitario Central, Oviedo); I. Parra (H Universitario Virgen de la Arrixaca, El Palmar); T. Pascual (H de Cabueñes, Gijón); A. Penas (Complejo Hospitalario Xeral-Calde, Lugo); J.A. Pérez (H Arnau de Vilanova, Valencia); P. Rivas (H Virgen Blanca, León); J. Sala (H Universitario Joan XXIII, Tarragona); M. Sánchez (Unidad Tuberculosis Distrito Poniente, Almería); P. Sánchez (H del Mar, Barcelona); E. Trujillo (Complejo Hospitalario de Ávila, Ávila); E. Valencia (H Carlos III, Madrid); A. Vargas (H Universitario Puerto Real, Cádiz); I. Vidal (Complejo Hospitalario Juan Canalejo, La Coruña); M. Vizcaya (Complejo Hospitalario Universitario de Albacete, Albacete); M. Zabaleta ( $\mathrm{H}$ de Laredo, Laredo); G. Zubillaga (H Donostia-San Sebastián, San Sebastián).

\section{References}

I. TB: A Global Emergency WHO Report on the TB Epidemic. Geneva: WHO/TB/94.I77.

2. WHO Report 2009: Global tuberculosis control - epidemiology, strategy, financing. [http://www.who.int/tb/publications/ global report/en/index.html]. Date last updated: March 242009. Date last accessed: arch 31 2009

3. Dye C, Scheele S, Dolin P, Pathania V, Raviglione MC: For the WHO Global Surveillance and Monitoring Project. Global Burden of Tuberculosis. Estimated Incidence, Prevalence, and Mortality by Country. JAMA 1999, 282:677-686.

4. INE: Series de población desde. 1996 [http://www.ine.es/jaxiBD/ tabla.do]. Date last updated: November I 2008. Date last accessed: November I 2008

5. Orcau A, Rius C, Garcia de Olalla P, Caylà JA: Programa de Prevención y Control de la TB de Barcelona. Informe 2007. Barcelona: Publicaciones de la Agència de Salut Pública de Barcelona 2008.

6. Caylà JA, Caminero JA, Rey R, Lara N, Vallés X, Galdós-Tangüis H, Working Group on Completion of Tuberculosis Treatment in Spain: Current status of treatment completion and fatality among tuberculosis patients in Spain. Int J Tuberc Lung Dis 2004, 8:458-64.

7. Veen J, Raviglione M, Rieder HL, Migliori GB, Graf P, Grzemska M, Zalesky R: Standardized tuberculosis treatment outcome monitoring in Europe. Recommendations of a Working Group of the World Health Organisation (WHO) and the European Region of the International Union Against Tuberculosis and Lung Disease (IUATLD) for uniform reporting by cohort analysis of treatment outcome in tuberculosis patients. Eur Respir J 1998, I 2:505-10.

8. Antoine D, French CE, Jones J, Watson JM: Tuberculosis treatment outcome monitoring in England, Wales and Northern Ireland for cases reported in $200 \mathrm{I}$. J Epidemiol Community Health 2007, $61: 302-7$.

9. Rodrigo T, Caylà JA, Galdós-Tangüis H, García de Olalla P, Brugal MT, Jansà JM: Proposing indicators for evaluation of tuberculosis control programmes in large cities based on the experience of Barcelona. Int J Tuberc Lung Dis 2001, 5:432-40.

10. Bloch AB, Cauthen GM, Simone PM, Kelly GD, Dansbury KG, Castro KG: Completion of tuberculosis therapy for patients reported in the United States in 1993. Int J Tuberc Lung Dis 1999, 3:273-80.

II. Jasmer RM, Seaman CB, Gonzalez LC, Kawamura LM, Osmond DH, Daley CL: Tuberculosis treatment outcomes. Am J Respir Crit Care Med 2004, 170:56I-66.

12. Farah MG, Tverdal A, Steen TW, Heldal E, Brantsaeter AB, Bjune G: Treatment outcome of new culture positive pulmonary tuberculosis in Norway. BMC Public Health 2005, 7:5-14.

13. Falzon D, Le Strat $Y$, Belghiti F, Infuso A, EuroTB Correspondents: Exploring the determinants of treatment success for tuberculosis cases in Europe. Int J Tubec Lung Dis 2005, 9:1 224-29.

14. Kliiman K, Altraja A: Predictors of poor treatment outcome in multi- and extensively drug-resistant pulmonary TB. Eur RespirJ 2009, 33:1085-94.

15. Duarte EC, Bierrenbach AL, Barbosa da Silva J Jr, Tauil PL, de Fátima Duarte E: Factors associated with deaths among pulmonary tuberculosis patients: a case-control study with secondary data. J Epidemiol Community Health 2009, 63:233-238.

16. Lefebvre N, Falzon D: Risk factors for death among tuberculosis cases: analysis of European surveillance data. Eur Respir J 2008, 31: 1256-60.

17. Oursler KK, Moore RD, Bishai WR, Harrington SM, Pope DS, Chaisson RE: Survival of patients with pulmonary tuberculosis: clinical and molecular epidemiologic factors. Clin Infect Dis 2002, 34:752-9.

18. Bustamante-Montes LP, Escobar-Mesa A, Borja-Aburto VH, GómezMuñoz A, Becerra-Posada F: Predictors of death from pulmonary tuberculosis: the case of Veracruz, Mexico. Int J Tuberc Lung Dis 2000, 4:208-I5.

19. World Health Organization: Tuberculosis and migration. [http:l /www.euro.who.int/tuberculosis/publications/2007/204 10]. Date last updated: December I 2008. Date last accessed: November I 2008

20. Grupo de Trabajo de los Talleres 2001 y 2002 de la Unidad de Investigación de Tuberculosis de Barcelona. Prevención y control de las tuberculosis importadas. Med Clín (Barc) 2003, | 2 |:549-62.

21. Martin-Casabona N, Alcaide F, Coll P, González J, Manterola JM, Salvadó $M$, Caylà JA: Farmacorresistencia de Mycobacterium tuberculosis. Estudio multicéntrico en el área de Barcelona. Med Clin (Barc) 2000, I I 5:493-98.

22. Pérez del Molino Bernal ML, Túñez V, Cruz-Ferro E, Fernández-Villar A, Vázquez-Gallardo R, Díaz-Cabanela D, Anibarro L, Grupo Gale de Estudio de Resistencias de M. tuberculosis: Tuberculosis. Study of Mycobacterium tuberculosis drug reistance in the region of Galicia, Spain. Int J Tuberc Lung Dis 2005, 9:1230-35.

23. Ruiz-Manzano J, Blanquer R, Calpe JL, Caminero JA, Caylà J, Domínguez JA, García JM, Vidal R, Spanish Society of Pulmonology and Thoracic Surgery: Diagnosis and treatment of Tuberculosis. Recommendations of the Society of Pneumology and Thoracic Surgery (SEPAR). Arch Bronconeumol 2008, 44:55I-66.

24. American Thoracic Society and Centers Disease, Control and Prevention: Treatment of Tuberculosis. Am J Respir Crit Care Med 2003, 167:603-66.

25. Joint Tuberculosis Committee of the British Thoracic Society: Chemotherapy and management of tuberculosis in the United Kingdom. Thorax 1998, 53:536-48.

26. Grupo de Estudio del Taller de 1999 de la Unidad de Investigación de Tuberculosis de Barcelona: Documento de Consenso sobre tratamientos directamente observados en tuberculosis. Med Clín (Barc) 2000, I I 5:749-57.

27. Marco A, Caylà JA, Serra M, Pedro R, Sanrama C, Guerrero R, Ribot $\mathrm{N}$ : Predictors of adherence to tuberculosis treatment in a supervised therapy programme for prisoners before and after release. Study Group of Adherence to Tuberculosis Treatment of Prisoners. Eur Respir J 1998, I 2:967-7I.

28. Ospina JE, Orcau A, Millet JP, Caylà JA, Casals M, Rius C, Sánchez F, the Barcelona Tuberculosis and Immigration Working Group: Effectiveness of Community Health Workers for the control of tuberculosis. Abstract Book, 40 th World Conference on Lung Health of the International Union Against Tuberculosis and Lung Disease (IUATLD). Int J Tuberc Lung Dis 2009, I3(suppI I):SI86. 